Review Article

\title{
The Role of Ovarian Sex Steroids in Metabolic Homeostasis, Obesity, and Postmenopausal Breast Cancer: Molecular Mechanisms and Therapeutic Implications
}

\author{
Viroj Boonyaratanakornkit ${ }^{1}$ and Prangwan Pateetin ${ }^{2}$ \\ ${ }^{1}$ Department of Clinical Chemistry, Faculty of Allied Health Sciences, Chulalongkorn University, \\ 154 Rama I Road Patumwan, Bangkok 10330, Thailand \\ ${ }^{2}$ Graduate Program in Clinical Biochemistry and Molecular Medicine, Thailand
}

Correspondence should be addressed to Viroj Boonyaratanakornkit; viroj.b@chula.ac.th

Received 31 July 2014; Accepted 6 October 2014

Academic Editor: Eileen M. McGowan

Copyright (C) 2015 V. Boonyaratanakornkit and P. Pateetin. This is an open access article distributed under the Creative Commons Attribution License, which permits unrestricted use, distribution, and reproduction in any medium, provided the original work is properly cited.

\begin{abstract}
Obese postmenopausal women have an increased risk of breast cancer and are likely to have a worse prognosis than nonobese postmenopausal women. The cessation of ovarian function after menopause results in withdrawal of ovarian sex steroid hormones, estrogen, and progesterone. Accumulating evidence suggests that the withdrawal of estrogen and progesterone causes homeostasis imbalances, including decreases in insulin sensitivity and leptin secretion and changes in glucose and lipid metabolism, resulting in a total reduction in energy expenditure. Together with a decrease in physical activity and consumption of a high fat diet, these factors significantly contribute to obesity in postmenopausal women. Obesity may contribute to breast cancer development through several mechanisms. Obesity causes localized inflammation, an increase in local estrogen production, and changes in cellular metabolism. In addition, obese women have a higher risk of insulin insensitivity, and an increase in insulin and other growth factor secretion. In this review, we describe our current understanding of the molecular actions of estrogen and progesterone and their contributions to cellular metabolism, obesity, inflammation, and postmenopausal breast cancer. We also discuss how modifications of estrogen and progesterone actions might be used as a therapeutic approach for obesity and postmenopausal breast cancer.
\end{abstract}

\section{Introduction}

The prevalence of obesity in many developed and developing countries has been increasing at an alarming rate reaching pandemic proportions over the past decade [1]. By the year 2030, the number of overweight and obese adults is projected to be 1.35 billion and 573 million individuals, respectively, worldwide [2]. A recent study estimated that one in five deaths in the United States is associated with obesity, surpassing smoking as Americans' number one killer [3]. Health problems that can be attributed to obesity include type 2 diabetes, cardiovascular diseases, hypertension, and cancer of several organs. While the relationship between obesity, diabetes, and cardiovascular diseases has been well studied and documented, the relationship between obesity and cancer has only started to receive much attention in recent years (see review [4]).
An increasing number of studies have highlighted the association between obesity and the risk of various cancers. It is estimated that $15-20 \%$ of all cancer deaths in the United States can be ascribed to obesity [5]. A recent study estimated that for every $5 \mathrm{~kg} / \mathrm{m}^{2}$ increase in body mass index (BMI), a risk for developing esophageal, thyroid, and colon cancer in males increased by $52 \%, 33 \%$, and $24 \%$, respectively, whereas the risk for developing endometrial and postmenopausal breast cancer in females increased by $59 \%$ and $12 \%$, respectively [6]. Interestingly, the association between obesity and postmenopausal breast cancer was found to be highest in women in the Asia-Pacific region with a $31 \%$ increase in postmenopausal breast cancer risk for every additional $5 \mathrm{~kg} / \mathrm{m}^{2}$ increase in BMI [6]. Epidemiological data suggests that women with breast cancer who are obese at the time of their diagnosis are more likely to 
have a worse prognosis than nonobese, lean women [7]. Prospective cohort studies showed about a twofold increase in breast cancer risk among postmenopausal women who had higher production of various sex steroid, including dehydroepiandrosterone sulfate (DHEAS), testosterone, estrone, and total estradiol (E2) and breast cancer risk was inversely correlated with the expression of steroid hormone binding globulin (SHBG) [8]. Analysis of several cohort studies indicated that the association of high BMI with increased breast cancer risk could be attributed mostly to elevated bioavailable E2 [9]. Mortality was also higher among obese women with breast cancer than leaner women [10]. Metaanalysis of 43 studies of comorbidity of obesity and breast cancer revealed that obese patients were 33\% more likely to die from breast cancer than nonobese patients. Recent evidence suggested that metabolic syndromes such as insulin resistance, hypertension, and hyperlipidemia increased the risk for postmenopausal breast cancer [11], suggesting a central role of ovarian sex steroids, estrogen, and progesterone, in regulating cellular metabolism, proliferation, and differentiation.

Obesity causes dysregulated metabolism and also provokes chronic inflammation in adipose tissue $[12,13]$. It is now widely accepted that cancer is involved in the alteration of cellular metabolism [14] and inflammation [15]. Ovarian sex steroids, estrogen, and progesterone and their cognate receptors (estrogen receptor (ER) and progesterone receptor $(\mathrm{PR})$ ) have also been shown to influence metabolism and inflammatory responses. Loss of the ovarian function to supply estrogen and progesterone after menopause can cause deregulation of the body's metabolism and inflammatory responses with increased risk of postmenopausal breast cancer. In this review, we will discuss and provide an integrated view of our current understanding of this complex relationship between ovarian sex steroids and their receptors in relation to obesity and inflammation and their contribution to postmenopausal breast cancer. Detailed molecular mechanisms of how ovarian sex steroids affect obesity and inflammation will also be discussed.

\section{Cancer and Metabolism}

Cancer is often associated with alterations in cellular metabolism. In 1920, Warburg found that cancer cells prefer to metabolize glucose by glycolysis as compared to oxidative phosphorylation even in the presence of ample oxygen [16]. While the Warburg effect is less efficient in producing ATP it is very effective in providing cellular building blocks and macromolecules such as amino acids, lipids, and nucleic acids [17], allowing cancer cells to rapidly proliferate. For example, pyruvate kinase $(\mathrm{PK})$, a rate-limiting step enzyme responsible for changing phoshphoenolypruvate (PEP) to pyruvate, is expressed in most cell types as four different isoforms PKL, PKR, PKM1, and PKM2. Embryo or stem cells express only PKM1 while proliferating and cancer cells express mainly PKM2 [18]. PKM2 is less effective in converting PEP into pyruvate resulting in a shortage of pyruvate available for the tricarboxylic acid (TCA) cycle, and oxidative phosphorylation, making a more favorable metabolic environment for glycolysis. Inhibition of PKM2 expression by short-hairpin RNA (shRNA) resulted in an increase in oxygen consumption and a decrease in pyruvate production [19].

A number of studies have suggested that tumor microenvironment promotes changes in cellular metabolism. Several factors have been shown to shift cellular metabolism toward aerobic glycolysis including ovarian sex steroid signaling, cellular microenvironment, obesity, and inflammation [2023]. Thus, the combined effect of menopause, obesity, and inflammation could create the right environment to foster development and progression of breast cancer. How these factors alter metabolic pathways and cellular metabolism will be discussed below.

\section{Menopause and Obesity}

3.1. Role of Estrogen and ER Signaling in Metabolic Control and Homeostasis. Postmenopausal women are more prone to gain weight. However, it is unclear why or how the menopausal transition leads to weight gain and increased breast cancer risk. The physiological withdrawal of ovarian sex steroids, estrogen, and progesterone has been implicated in altered metabolism after menopause. Estrogens have been shown to play an important role in metabolic control and homeostasis. There are three forms of estrogen in women, estrone (E1), estradiol (E2), and estriol (E3). The major and most potent circulating estrogen in women throughout the reproductive years is E2. A key enzyme that aromatizes androgen into estrogen and is required for E2 biosynthesis is a member of P450 enzyme family, aromatase [24]. Metaanalysis of several clinical studies revealed a connection between E2 and control of several key metabolic functions including abdominal obesity, insulin sensitivity, lipid transport, blood pressure, and inflammatory or prothrombotic states [25].

3.2. Role of E2/ER in Insulin-Sensitivity and Glucose Uptake. $\mathrm{E} 2$ and estrogen receptors $(\mathrm{ER} \alpha$ and $\mathrm{ER} \beta)$ are involved in blood glucose and lipid homeostasis [26]. ER $\alpha$ knockout $(\mathrm{ER} \alpha \mathrm{KO})$ mice as well as aromatase knockout (ArKO) mice are obese and insulin resistant [27, 28]. Mutation of the aromatase gene or males with genetic ER $\alpha$ deficiency developed insulin resistance and glucose intolerance [29, 30]. Microarray analysis revealed that genes involved in hepatic and lipid biosynthesis were upregulated while genes involved in lipid transport were decreased in ER $\alpha \mathrm{KO}$ mice. Interestingly, ER $\beta$ knockout (ER $\beta \mathrm{KO}$ ) mice showed normal glucose tolerance and insulin release, suggesting that $\operatorname{ER} \beta$ at most plays a minor role in regulating body's metabolism [31]. Deletion of $\mathrm{ER} \alpha$ gene in mouse myeloid cells showed adipose tissue inflammation with insulin resistance, acceleration of atherosclerotic lesion, and obesity [32]. Several lines of evidence indicate that $\mathrm{ER} \alpha$ is the major form of ER that plays a predominant role in regulating glucose and lipid metabolism [27, 32, 33]. ER $\alpha$ plays a central role in regulating metabolism and physical activities in the brain [34, 35]. Mice lacking ER $\alpha$ in the hypothalamic steroidogenic factor 1 neuron showed a significant decrease in energy expenditure and an increase in abdominal fat [35]. Ovariectomized 
(OVX) mice fed with high fat diet showed increased adiposity and insulin insensitivity, and E2 treatment improved insulin sensitivity and reduced liver fat deposit. However, E2 failed to improve insulin resistance and fatty liver induced by highfat diet in hepatocyte-specific $\mathrm{ER} \alpha \mathrm{KO}$ mice [33]. In addition, $\mathrm{ER} \alpha$ could help induce insulin sensitivity through GLUT4, a major insulin-stimulated glucose transporter in muscle cells and adipocytes. In aging female rats, E2 treatment increased insulin sensitivity and improved glucose homeostasis through increasing GLUT4 expression in muscle cells [36]. The E2 increase of GLUT4 expression is likely mediated through $\mathrm{ER} \alpha$ since $\mathrm{ER} \alpha \mathrm{KO}$ mice are glucose intolerant and insulin resistant [28]. On the other hand, both glucose tolerance and insulin sensitivity in ER $\beta \mathrm{KO}$ mice are normal or better than their wild-type littermates [31]. Together, these data suggest that $\mathrm{E} 2$ through $\mathrm{ER} \alpha$ regulates insulin sensitivity and lipid biosynthesis and transport.

How E2 and ER $\alpha$ mediate an increase in insulin sensitivity and decrease adiposity is likely to be multifactorial. ERs are expressed in all metabolically important tissues including brain, adipose tissue, skeletal muscle, and pancreas [37]. E2 suppresses accumulation of white adipose tissue (WAT) by decreasing fatty acid and triglyceride synthesis. OVX female mice treated with E2 showed a decrease in adipocyte size by reducing fatty acid uptake through decreasing lipoprotein lipase expression, by reducing lipogenesis through decreasing acetyl-coA carboxylate and fatty acid synthase expression, and by increasing lipolysis through catecholamine activation [38].

3.3. Role of E2/ER $\alpha$ in Cellular Metabolism of Glucose and Lipid Metabolism. At the cellular level, E2 and ER $\alpha$ have been shown to directly regulate glucose and lipid metabolism. $\mathrm{E} 2 / \mathrm{ER} \alpha$ affects several key processes of glucose metabolism including glycolysis, the TCA cycle, and oxidative phosphorylation [39]. E2 increases the expression and activities of several key glycolytic enzymes. Glycolysis in MCF-7 breast cancer cells was shown to be induced by E2 and inhibited by tamoxifen (TAM) [40]. E2 induced several key glycolytic enzymes in the cytosol such as hexokinase (HK), phosphofructokinase (PFK), and pyruvate kinase (PK) in the female rat brain after 4 hours of treatment [41]. Proteomic analysis of E2-regulated proteins in the bones of female mice found that both glycolytic enzymes, enolase and pyruvate kinase isoform M2 (PKM2), were regulated by $\mathrm{E} 2$ [42]. In addition, $\mathrm{E} 2 / \mathrm{ER} \alpha$ also regulated several key enzymes of the TCA cycle found in the inner membrane of the mitochondria. Treatment of OVX rats with E2 increased the activity of citrate synthase, a key enzyme condensing an acetyl group from acetyl-CoA with oxaloacetate to form citrate in TCA cycle, in muscle cells and in cerebral blood vessel cells $[43,44]$. Proteomic analysis of brain mitochondrial proteins after treatment of OVX rats with E2 for 24 hours showed significant increased expression of aconitase, pyruvate dehydrogenase isoform E1b and E2, and malate dehydrogenase, as well as enzymes coupling TCA with amino acid synthesis such as 2-oxoglutarate dehydrogenase and glutamine dehydrogenase [45]. These data underscore the significance of E2/ER in regulating glucose metabolism in glycolysis and the TCA cycle. Local production of E2 after menopause could create a microenvironment conducive to aerobic glycolysis metabolism to promote cell proliferation and cancer development.

Oxidative phosphorylation occurs in the mitochondrial inner membrane and generates the majority of cellular energy in the form of ATP, NADH, and FADH [39]. Studies have shown the significance of ERs in mitochondria and oxidative phosphorylation. Both forms of ERs, $\mathrm{ER} \alpha$ and $\mathrm{ER} \beta$, have been shown to localize to the mitochondria in several E2target cells including uterine cells, neurons, cardiomyocytes, bone cells, hypothalamic cells, endothelial cells, liver cells, and breast cancer cells [46-50]. Thirteen proteins in the mitochondrial respiratory chain complexes are encoded by the mitochondrial DNA (mtDNA) within the mitochondria, whereas the majority of proteins required for mtDNA replication, transcription, and translation are encoded by nuclear DNA. Several studies in various cell types have demonstrated that E2 stimulated mtDNA transcription [44, $48,51,52]$, and ICI182780, a pure ER antagonist, inhibited E2-induced mtRNA gene expression [48], demonstrating the significance of E2 and mitochondrial ER in regulating mtDNA gene transcription. E2 not only activated mtDNA gene transcription, but also induced expression of nuclear DNA of genes encoding MRC proteins leading to E2-induced mitochondrial respiration [39]. Together, these data suggest that E2/ER coordinately induces transcription of mtDNA and nDNA encoding respiratory chain subunits and other regulatory proteins required for mitochondria replication and function. Therefore, E2 withdrawal or defects in ER functions could result in a decrease in mitochondrial respiration and a reduction in energy expenditure. In fact, OVX-induced obesity in mice was associated with decreased oxygen consumption, indicating a reduction in energy expenditure in the absence of E2 [21]. Similar reduction in energy expenditure in the mitochondria could also be observed in women after menopause [53].

E2 also plays an important role in fatty acid $\beta$-oxidation. Analysis of liver collected from aromatase knockout mice with undetectable levels of E2 revealed a reduction of mRNA expression and activity of enzymes involved in fatty acid metabolism. E2 treatment of aromatase knockout mice restored mRNA expression and increased activity of fatty acid metabolism enzymes [54]. Analysis of adipose tissue and muscle from female mice at 2-4 weeks after ovariectomy showed that nuclear receptors and proteins required for efficient energy expenditure such as PPAR $\gamma, \operatorname{PPAR} \delta$, PCG1 $\alpha, \operatorname{PCG} 1 \beta$, and ERR1 were all reduced as compared to sham-operated control mice [55]. In addition, expression of enzymes involved in fatty acid $\beta$-oxidation and transcription factors required for lipolysis were also decreased [55]. Thus, depletion of E2 by ovariectomy or during menopause may lead to a decrease in expression of genes required for efficient energy expenditure and genes for fatty acid or lipid catabolism which may contribute, in part, to obesity after menopause.

3.4. Role of E2/ER in Adipokine Signaling. In addition to directly affecting adipocyte metabolism, E2/ER signaling 
interacts with adipokine, leptin, and adiponectin signaling [56]. Leptin regulates energy intake and expenditure, and leptin levels are directly proportional to the amount of adipose tissue in the body. Leptin binds to leptin receptors in the hypothalamus and inhibits appetite and food intake (see review [57]). Studies have shown that E2 may mediate antiobesity effects through $\mathrm{ER} \alpha$ in the hypothalamus, in the ventral medial nucleus (VL VMN), and the arcuate (ARC), by increasing expression of leptin receptors, thus increasing leptin sensitivity when E2 levels are higher [58]. Leptin levels correlate with the levels of estrogen in premenopausal women; however, this correlation between leptin and estrogen often disappears in postmenopausal women and could help explain a rise in obesity in the postmenopausal woman population [59].

Adiponectin is an important adipokine that is produced by adipose tissue and regulates peripheral glucose and insulin levels [60]. Studies suggest that $\mathrm{ER} \alpha$ is a positive regulator of adiponectin levels in adipose tissue. After menopause, there is a shift in the balance between $\operatorname{ER} \alpha$ and $\operatorname{ER} \beta$ in adipose tissue, with $\mathrm{ER} \beta$ becoming more dominant [61]. Secretion of adiponectin from adipose tissue is stimulated by peroxisome proliferator activated receptor gamma (PPAR $\gamma)$. $\operatorname{ER} \beta$ has been shown to reduce PPAR $\gamma$-expression and activity resulting in a reduction in adiponectin secretion from adipose tissue [62] and may result in decreased insulin levels associated with menopause. More studies will be needed to determine the role of adiponectin in metabolic disorder such as menopause-induced obesity.

Therefore, E2 withdrawal in postmenopausal women could lead to a decrease in insulin and leptin sensitivity and a decrease in mitochondria oxidative phosphorylation and lipid metabolism. These changes in glucose and lipid uptakes along with a decrease in carbohydrate and lipid metabolism render postmenopausal women less efficient in energy expenditure and more susceptible to obesity after E2 withdrawal.

\section{Molecular Mechanism of Metabolic Control by ERa: Master Regulator of Glucose and Lipid Metabolism}

Different forms of ERs mediate distinct functions of E2. Recent data strongly indicates that the beneficial effects of E2 on metabolic regulation are mediated through ER $\alpha$. $\mathrm{ER} \alpha$ is a member of the nuclear receptor superfamily and comprises six modular domains including the N-terminal domain or the A/B domain, DNA binding domain, hinge region, ligand binding domain, and the $\mathrm{C}$-terminal or the $\mathrm{E}$ domain $[63,64]$. ER $\alpha$ contains two activation functions (AFs) with AF-1 in the A/B domain and AF-2 in the ligand binding domain [65]. ER $\alpha$ can mediate its biological effects through nuclear and extranuclear signaling [63]. In nuclear signaling, ER $\alpha$ directly binds to estrogen response elements (ERE) or interacts with other transcription factors to regulate gene transcription in the nucleus. In extranuclear signaling, $\mathrm{ER} \alpha$ interacts with cytoplasmic signaling molecules or other signal transduction scaffolding proteins and activates many key cytoplasmic signaling pathways (see review $[66,67]$ ). A recent study suggested that the AF2 domain is essential for E2-mediated control of glucose homeostasis [68]. Mice expressing a mutant ER $\alpha$ lacking the AF2 domain rapidly gained weight and became severely obese with insulin resistance and glucose intolerance symptoms, similar to $\mathrm{ER} \alpha$ knockout mice, whereas mice expressing a mutant $\mathrm{ER} \alpha$ lacking the AF1 domain had similar body weight and metabolic functions to wild-type mice. E2 treatment in mice with wild type or AF-1-deleted ER $\alpha$ showed increased energy expenditure and insulin sensitivity but failed to show these beneficial metabolic effects in mice with AF-2-deleted ER $\alpha$ [68].

However, detailed molecular mechanisms of how ER $\alpha$ mediated its beneficial metabolic effects are not well understood. Mice expressing the $\mathrm{ER} \alpha$ mutant with disrupted ERE binding showed a decrease in body weight, improved insulin sensitivity, and increased energy expenditure after E2 treatment. These data suggested that ER $\alpha$ likely mediated its metabolic effects in an ERE-independent manner, possibly through tethering with other transcription factors such as activator protein-1 (AP-1), specificity protein 1 (Sp1), or nuclear factor $\kappa \mathrm{B}(\mathrm{NF}-\kappa \mathrm{B})$ [69]. More studies will be required to determine the role of AF2 in E2-mediated EREindependent signaling of $\mathrm{ER} \alpha$ in metabolic regulation. $\mathrm{ER} \alpha$ activation through AF-1 or through both AF-1 and AF-2 has been shown to promote breast cancer proliferation [70]; however, only AF-2 activation is needed for $\operatorname{ER} \alpha$-mediated metabolic regulation. Therefore, it would be of great interest therapeutically to develop an ER $\alpha$ AF-2 agonist to harness the beneficial metabolic effects of ER $\alpha$ without the harmful effects of ER $\alpha$ AF-1 [71].

\section{Role of Progesterone and PR Signaling in Metabolic Control and Homeostasis}

After menopause, cessation of ovarian functions leads to the withdrawal of both estrogen and progesterone. While the role of E2/ER signaling in metabolic controls has been well documented, how progestins and PR signaling influences metabolic control and homeostasis is still unclear. Biological effects of progestin are mediated through PR. PR exits as two isoforms: full-length PR-B and 164-amino acid N-terminal truncated, PR-A [72]. The two isoforms of PR play distinct roles both in vitro and in vivo. In most cases, PR-B acts as a stronger transcriptional activator as compared to PRA. PR-A can ligand-dependently act as a transcriptional repressor of ER, androgen receptor (AR), or glucocorticoid receptor (GR) [73]. Selective deletion of the PR isoform showed distinct functions in vivo $[74,75]$. PR mediates its actions by binding ligands, translocating into the nucleus, and directly binding to DNA or nuclear signaling. In addition, PR can also directly interact with cytoplasmic signaling molecules and activate cytoplasmic signaling pathways such as Src/Ras/Raf/MAPK [76], PI3K/Akt, or Src/Stat3 [77] (see review [78]). Progesterone regulates genes that are involved in RNA and protein processing, cell cycle, apoptosis, and cellular metabolism [79]. Microarray gene expression studies showed that PR regulates several important genes involved 
in cholesterol or steroid metabolism and trafficking, fatty acid and lipid metabolism, and nucleotide and amino acid metabolism in breast cancer cells [79].

The role of progesterone/PR signaling in metabolic control is not well understood. PRs have been shown to be expressed in adipocytes [80], where they prevent lipolysis in rat adipose tissue [81]. A recent study showed that progesterone inhibits glucose uptake in 3T3-L1 adipocytes through a decrease in IRS-1 expression leading to a decrease in IRS phosphorylation, the association of IRS-1 with $\mathrm{p} 85$, and a subsequent decrease in Akt1 and Akt2 phosphorylation [82]. Progesterone activates glycogen phosphorylase (a rate-limiting step in glycogenolysis) or the breakdown of glycogen through an extranuclear signaling pathway independent of cAMP leading to increased blood glucose levels [83]. Rats treated with progesterone for 14 days showed a decrease in GLUT4 in both adipose and skeletal muscle cells [84]. While estrogen appears to increase the capacity of carbohydrate and lipid metabolism, progesterone seems to abolish estrogen-induced metabolic effects in skeletal muscle cells [84]. However, progesterone appears to exert different metabolic influences in cancer cells. In breast cancer cells medroxyprogesterone acetate (MPA) treatment for 6 days increased glucose uptake and fatty acid synthase (FASN) and activation of stearoylCoA desaturase-1 (SCD-1). These changes in FASN and SCD1 activities increased monounsaturated fatty acid production and contributed to an increase in cellular phospholipids, triglycerides, and formation of lipid droplets in breast cancer cells [85].

Effects of progesterone on metabolic control have been extensively studied in gestational diabetes. Progesterone levels increase to support embryo transplantation and inhibit ovulation during pregnancy. Hepatic glucose production increases $15-30 \%$ to accommodate fetal needs, which is compensated by a $50-70 \%$ decrease in insulin-stimulated glucose uptake in late pregnancy [80]. This decrease in insulin sensitivity or insulin resistance is one of a number of the metabolic changes associated with pregnancy, and 3-7\% of pregnant women develop impaired glucose tolerance or diabetes [81]. Pregnancy is an altered metabolic state where there is an increase in the production of insulin from $\beta$ cells to facilitate an increase in glucose uptake. However, progesterone could also alter insulin insensitivity. Pregnant rats treated with progesterone are more insulin resistant than placebo-treated control rats [82]. Studies suggest that progesterone-induced insulin resistance may be due to reductions in Glut4 expression and glucose uptake in skeletal muscle cells [83]. In C57BL/6 mice, nonfasting plasma glucose is correlated with progesterone levels [86]. High dose progesterone treatment accelerated the progression of diabetes in female obese diabetic-prone $\mathrm{db} / \mathrm{db}$ mice and treatment with RU486 increased insulin and reduced blood glucose levels in both wild-type and $\mathrm{db} / \mathrm{db}$ mice [86].

PR knockout mice showed lower fasting blood sugar and improved glucose tolerance compared to wild-type mice due to enhanced insulin secretion caused by an increase in $\beta$-cell proliferation and $\beta$-cell mass [86]. Interestingly, PR knockout improved insulin sensitivity only in female mice, not in male mice, suggesting that other factors, other than
PR, might play a role in insulin sensitivity in males. A recent study showed that PR activation enhanced the proinflammatory cytokine- PIC-induced cell injury in Min6 mouse pancreatic islet $\beta$-cells, possibly through an increase in the mitogen-activated protein kinase (MAPK) signaling and p53 expression and a decrease in Akt signaling. A nonsteroidal PR antagonist or PR siRNA interference protected $\beta$-cells from PIC-induced injury [87]. Together, these data suggest that progestin-mediated activation of PR could have adverse effects on insulin sensitivity possibly through a decrease in insulin secretion. In postmenopausal women, the absence of progesterone is likely to enhance insulin production and could promote insulin resistance. In addition, progesterone via $P R$ has been shown to activate expression of insulin-like growth factor binding protein-1 (IGFBP1) that sequesters and inhibits insulin-like-growth factor-I (IGF-I) action [88, 89]. Physiological withdrawal of progesterone after menopause could make IGF-1 more available to promote cell proliferation. Along with the dysregulated metabolic state induced by estrogen withdrawal, the combination of both estrogen and progesterone withdrawal in postmenopausal women could strongly increase the risk for obesity and breast cancer. Together, these data suggest the interplay of obesity, ER PR expression, and breast cancer aggressiveness. However, more studies will be required to examine detailed molecular mechanisms of these interactions. Better understanding of these interactions will help us to develop better and more effective treatments for postmenopausal breast cancer.

\section{Obesity and Inflammation Increase Risk for Postmenopausal Breast Cancer}

It is well established that chronic inflammation increases cancer risk [90]. Obesity is associated with adipose tissue inflammation, characterized by macrophage infiltration into the adipose deposit [12]. In addition, large adipose deposits in obese individuals could have limited blood supply resulting in adipose tissue hypoxia [91] and induction of hypoxicinducible factor 1- $\alpha$ (HIF- $\alpha$ ) expression in adipocytes. HIF1 $\alpha$ in turn stimulates expression of monocyte chemotactic factor 1 (MCP1), promoting macrophage recruitment to adipose deposits. In addition, production of saturated fatty acids by the breakdown of large fat droplets in large adipocytes in obese individuals can lead to activation of caspase1 , interleukin- $\beta$, and the NF- $\kappa \mathrm{B}$ signaling cascade [92]. Together, adipocytes and macrophages in adipose tissue induce expression of inflammatory cytokines such as TNF- $\alpha$, IL-6, and prostaglandin-E2 (PGE2) [90] (Figure 1).

Both TNF $\alpha$ and PGE2 have been shown to stimulate expression of aromatase in adipose tissues and increase the risk of breast cancer, especially in obese postmenopausal women $[93,94]$. Expression of aromatase in fibroblasts or stromal cells surrounding the adipocytes and mammary ducts helps to convert circulating androgen into estrogens in the breast. Examination of aromatase activity and expression of aromatase in breast tissues from different quadrants surrounding breast tumors found that aromatase activity and expression were highest in the quadrant that contained the tumor and decreased with increasing distance away from 
the tumor $[95,96]$. The increase in the aromatase expression was shown to be largely due to the levels of PGE2 produced by the tumor, suggesting that inflammatory cytokines were produced by the adipocytes and tumors of obese women [96]. $\mathrm{TNF} \alpha$ via $\mathrm{NF} \kappa \mathrm{B}$ signaling stimulates aromatase expression through CYP19A1 (aromatase) promoter I.4 by stimulating the binding of $\mathrm{c}$-Fos and c-Jun transcription factors to the activation protein-1 (AP-1) element upstream of promoter I.4, while PGE2 stimulates aromatase expression through promoter II/I.3 of the human CYP19A1 gene [13]. Recent studies showed the presence of crown-like structures, macrophages surrounding large lipid-filled adipocytes of obese subjects, in the breasts of obese women [97]. The presence of these crown-like structures correlated with an increase in $\mathrm{NF} \kappa \mathrm{B}$ expression and elevated aromatase activity [97]. Further study indicated that the increase in aromatase expression correlated with an increase in the activity of the CYP19A1 proximal II/I.3 promoter and is associated with an increase in the cyclooxygenase-2 (COX2) expression and PGE2 levels in the breasts of obese women [93].

\subsection{Molecular Mechanism of ER and PR Crosstalk with NFкB} Inflammatory Signaling Pathway. The NFkB pathways play crucial roles in the inflammation process in several tissues including mammary adipose tissues [98]. The influence of ovarian sex steroids on $\mathrm{NF} \kappa \mathrm{B}$ signaling has been well documented. Both ER and PR have been shown to regulate cellular inflammation through interacting with $\mathrm{NF} \kappa \mathrm{B}$ signaling pathways [98]. Constitutive activation of $\mathrm{NF} \kappa \mathrm{B}$ signaling promotes the development of hormone-independent breast tumors [99]. Obese postmenopausal women have an increased risk for developing steroid hormone receptor positive breast cancer [100]. NFאB activation in ER+ postmenopausal breast cancer is associated with endocrine resistance and a more aggressive phenotype [101]. Studies have demonstrated that ER interacts with RelA/p65, a member of the $\mathrm{NF} \kappa \mathrm{B}$ family, and synergistically regulates expression of a group of genes that are important in regulating breast cancer cell survival and chemoresistance. ER interacts with RelA and enhances binding of both ER and RelA to ERE, resulting in activation of prostaglandin-E synthase-1 (PGES) gene expression leading to an increase in PGE2 production [102]. High levels of PGE promote breast cancer invasiveness, angiogenesis, and expression of aromatase in stromal and adipose tissue in the breast $[103,104]$. In addition, ER can crosstalk with the $\mathrm{NF} \kappa \mathrm{B}$ pathway through interaction between ER and $\mathrm{I} \kappa \mathrm{B}$ Kinase $\alpha(\mathrm{I} \kappa \mathrm{K} \alpha)$ at promoters of ER target genes, important for breast cancer cell-cycle progression including cyclin-D1 and E2F1 $[105,106]$. Together these studies demonstrate that obesity could promote inflammation and the development of more aggressive, invasive breast cancer phenotypes and chemo- and endocrine resistant breast cancers.

In some cases, ER has been shown to repress $\mathrm{NF} \kappa \mathrm{B}$ activity and may be involved in anti-inflammatory effects of E2. ER inhibits $\mathrm{NF} \kappa \mathrm{B}$ signaling through $\mathrm{NF} \kappa \mathrm{B}$ DNA binding or $\mathrm{NF} \kappa \mathrm{B}$ transcriptional activation [107]. ER represses expression of RelB, a member of the $\mathrm{NF} \kappa \mathrm{B}$ family, by directly or indirectly preventing $\mathrm{NF} \kappa \mathrm{B}$ and $\mathrm{AP}-1$ interaction at the RelB promoter, resulting in formation of an unfavorable DNA complex for transcriptional activation [108]. In addition, a study by Nettles and colleagues suggested that transrepression of NF $\kappa$ B activity by ER may occur through a competition between $\mathrm{ER}$ and $\mathrm{NF} \kappa \mathrm{B}$, displacing $\mathrm{cAMP}$ response elementbinding protein-binding protein $(\mathrm{CBP}) / \mathrm{p} 300$ coactivator from the promoter of $\mathrm{NF} \kappa \mathrm{B}$ target genes and resulting in suppression of $\mathrm{NF} \kappa \mathrm{B}$ target genes [109].

Increasing evidence suggests that PR plays a significant role in anti-inflammatory responses in breast cancer cells $[110,111]$. Interestingly, lack of PR in ER+ breast cancer is associated with less differentiated, more aggressive breast tumors that are resistant to endocrine therapies [112]. A recent study demonstrated that PR through progestin-dependent and independent mechanisms decreased expression of aromatase, COX-2, and HER-2/neu [111]. PR expression or progesterone treatment was shown to increase the expression of the nuclear factor $-\kappa \mathrm{B}$ inhibitor $(\mathrm{I} \kappa \mathrm{B} \alpha)$. Expression of $\mathrm{I} \kappa \mathrm{B} \alpha$ positively correlated with PR expression in 28 breast cancer cell lines [110]. Gene expression analysis in both normal mammary epithelial and breast cancer cells revealed that $\mathrm{PR}$ inhibited $\mathrm{NF} \kappa \mathrm{B}$ target genes through interacting with DNA-bound RelA/p65, resulting in transcription inhibition of $\mathrm{NF} \kappa \mathrm{B}$ target genes. $\mathrm{PR}$ inhibited transcription of $\mathrm{NF}-\kappa \mathrm{B}$ target genes through two different mechanisms: activation function-2 (AF-2) dependent and AF-2 independent [111]. Agonist-bound $\mathrm{PR}$ repressed the AF-2 dependent class of genes while the AF-2 independent class of genes was equally sensitive to both PR agonists and antagonists. Together, these studies suggested that the anti-inflammatory effect of PR is likely mediated through multiple mechanisms. PR agonists may inhibit some $\mathrm{NF} \kappa \mathrm{B}$ target genes but may not affect others. More studies will be needed to exploit the antiinflammatory role of PR and to design specific PR ligands to selectively inhibit $\mathrm{NF} \kappa \mathrm{B}$ target genes that are crucial for the development and progression of breast cancer. Collectively, these data suggest an association between ER PR expression and obesity induced inflammation. Chronic inflammation induced by adipocytes and macrophages in adipose tissue could be further modulated by ER or PR signaling. Thus, interfering with ER PR signaling may help reduce obesity induced inflammation and decrease the incidence of breast cancer in obese postmenopausal women.

\subsection{Possible Role of ER, PR in Obesity-Induced Inflammation and Postmenopausal Breast Cancer: Clinical Evidences and In Vivo Models. Systemic analyses of clinical studies have suggested that obese postmenopausal women have almost a twofold increase in hormone receptor positive $(\mathrm{ER}+/ \mathrm{PR}+)$ breast cancer [113]. Data from several in vitro and in vivo stud- ies indicated that chronic inflammation induced by obesity causes an increase in inflammatory mediators, leading to an increase in aromatase activity and expression in adipocytes and hormone-dependent breast cancer. Extragonadal local E2 production, induced by chronic inflammation, in the breast of obese postmenopausal women supplies breast epithelial cells with E2 and increases the risk for breast cancer by promoting the growth of hormone receptor positive breast cancer in these women.}


In vivo models of diet-induced obese animals have provided further support for obesity and development of breast cancer in postmenopausal women. In a recent study in a dietinduced obesity model, Wistar rats were fed with a high fat diet and were classified into three categories: obese, midweight, and lean [21]. Mammary tumors were induced by a single injection of 1-methyl-1-nitrourea (MNU) into rats at about age 52 days. MNU-induced rat mammary tumors are similar to breast tumors seen in human breasts in term of percentage of intraductal tumors and pattern of progression and steroid receptor positivity [114]. Rats in the obese group were allowed to gain weight under the obesogenic conditions of high-fat diet and were restricted to limited physical activity; and some rats were also ovariectomized (OVX) at 19 weeks of age (obese-OVX). Tumor numbers were similar in all groups before OVX. After OVX, obese-OVX group showed almost a twofold increase in tumor numbers as compared to pre-OVX values while tumor numbers remained relatively the same in lean-OVX and mid-weight OVX-rats. Seventy percent $(70 \%)$ of tumors in obese-OVX group expressed high ER $\alpha$ levels as compared to $30 \%$ of mammary tumors from non-obese-OVX rats, similar to breast tumors seen in obese postmenopausal women with a high portion of tumors classified as receptor-positive. It is likely that extragonadal local E2 production in adipose tissue of OVX-obese animals fostered the development of ER+ tumors.

An association of obesity and progesterone receptor positivity in mammary tumors has recently been demonstrated in an in vivo obesity and overfeeding rat model conducted in the MacLean laboratory [20]. Rats were classified into four groups, including obesity-prone (obese) and obesity-resistant (lean) groups and heaviest and lightest groups. These groups were further subdivided into low and high energy excess group based on energy expenditure within the last 48 hour prior to sacrifice. Mammary tumors from obese animals with high-energy excess had statistically significantly higher glucose uptake than that of tumors from obese with low-energy excess and lean rats. While lean animals preferred to deposit excess nutrients in mammary and peripheral tissues, obese animals deposited their excess nutrients into their mammary tumors. Interestingly, tumors from obese animals showed an increase in PR expression, mainly the PR-A isoform in preference to the PR-B isoform [20]. Furthermore, elevated PR expression was positively correlated with expression of glycolytic and lipogenic enzymes, glucose uptake, and proliferation markers in mammary tumors. Treatment with metformin, an antidiabetic drug, during OVX-induced obesity resulted in tumor regression and a decrease in $\mathrm{PR}$ expression [20]. Consistent with in vivo findings, analysis of expression microarrays of breast tumors from postmenopausal women revealed that $\mathrm{PR}+$ tumors had an increase in metabolic enzymes similar to that of $\mathrm{PR}+$ tumors from the obese-prone rat model, suggesting that $\mathrm{PR}+$ breast tumors have increased metabolic activities. Interestingly, PR-A has been shown to induce inflammatory processes in the mammary gland by promoting leukocyte recruitment to mammary epithelium [115]. Data obtained from these animal models are consistent with increased risk of developing hormone receptor positive breast cancer among obese postmenopausal women [7].
These studies also suggested that expression of PR-A in breast tumors enhanced metabolic capacity and induced proinflammatory responses in breast cancer. Most clinical studies reported PR positivity in breast tumor specimens without isoform specification. Therefore, future studies will be needed to determine the role of $\mathrm{PR}$ isoforms in breast cancer metabolism and aggressiveness.

\section{Conclusion and Future Perspectives}

How the cessation of ovarian functions and withdrawal of ovarian steroids, E2 and progesterone, promote postmenopausal obesity and contribute to the development of hormone receptor positive breast cancer is summarized in Figure 1. The lack of estrogen and progesterone after menopause can cause an imbalance in a woman's homeostasis. The lack of estrogen can bring about a decrease in insulin sensitivity and glucose uptake and a decrease in glucose metabolism and mitochondria respiration. The lack of ovarian steroids, especially estrogen, could lead to a reduction in cellular metabolism and a reduction in total energy expenditure. Reduction in energy expenditure together with lack of physical activities and high fat diet promote postmenopausal weight gain and obesity [116]. Large fat deposits in obese women could limit blood and oxygen supply to the area and can result in tissue hypoxia. A hypoxic state induces expression of HIF1 $\alpha$ and inflammation by promoting macrophage recruitment and secretion of inflammatory cytokines such as IL-6, IL-1 $\beta$, PGE2, and TNF $\alpha$. In addition, induction of HIFl $\alpha$ may also cause a shift in cellular metabolism to favor aerobic glycolysis often found in actively proliferating or cancer cells. The breakdown of large lipid droplets in obese women could cause an increase in saturated fatty acid (FAS) production and activation of inflammatory signaling pathways such as $\mathrm{NF} \kappa \mathrm{B}$ activation. The release of inflammatory cytokines and activation of the $\mathrm{NF} \kappa \mathrm{B}$ pathway help activate the CYP19A1 promoter and increase aromatase gene expression. Aromatase expression in the adipose tissue helps produce extragonadal estrogen from androgen in the surrounding tissues. Studies, as described in this review, suggest that obese women have lower levels of SHBG. Local extragonadal estrogen production together with low SHBG makes estrogen readily available to enhance the growth of ER+ breast cancer cells. Furthermore, obesity and the lack of ovarian sex steroids could help promote an insulin-resistant state with high circulating insulin and IGF-I. Leptin production from adipocytes is increased in obese individuals and increasing evidence shows a positive correlation between increasing leptin levels and the risk for postmenopausal breast cancer [117]. High levels of circulating IGF-1, insulin, and leptin may help promote the development and growth of breast cancer cells in postmenopausal women. Together, these data demonstrate a link between ovarian sex steroids, obesity, and inflammation with postmenopausal breast cancer.

While several advances have been made in our understanding of the role of ovarian steroids and their receptors on postmenopausal breast cancer, many important factors remain unclear and will need to be further explored to 


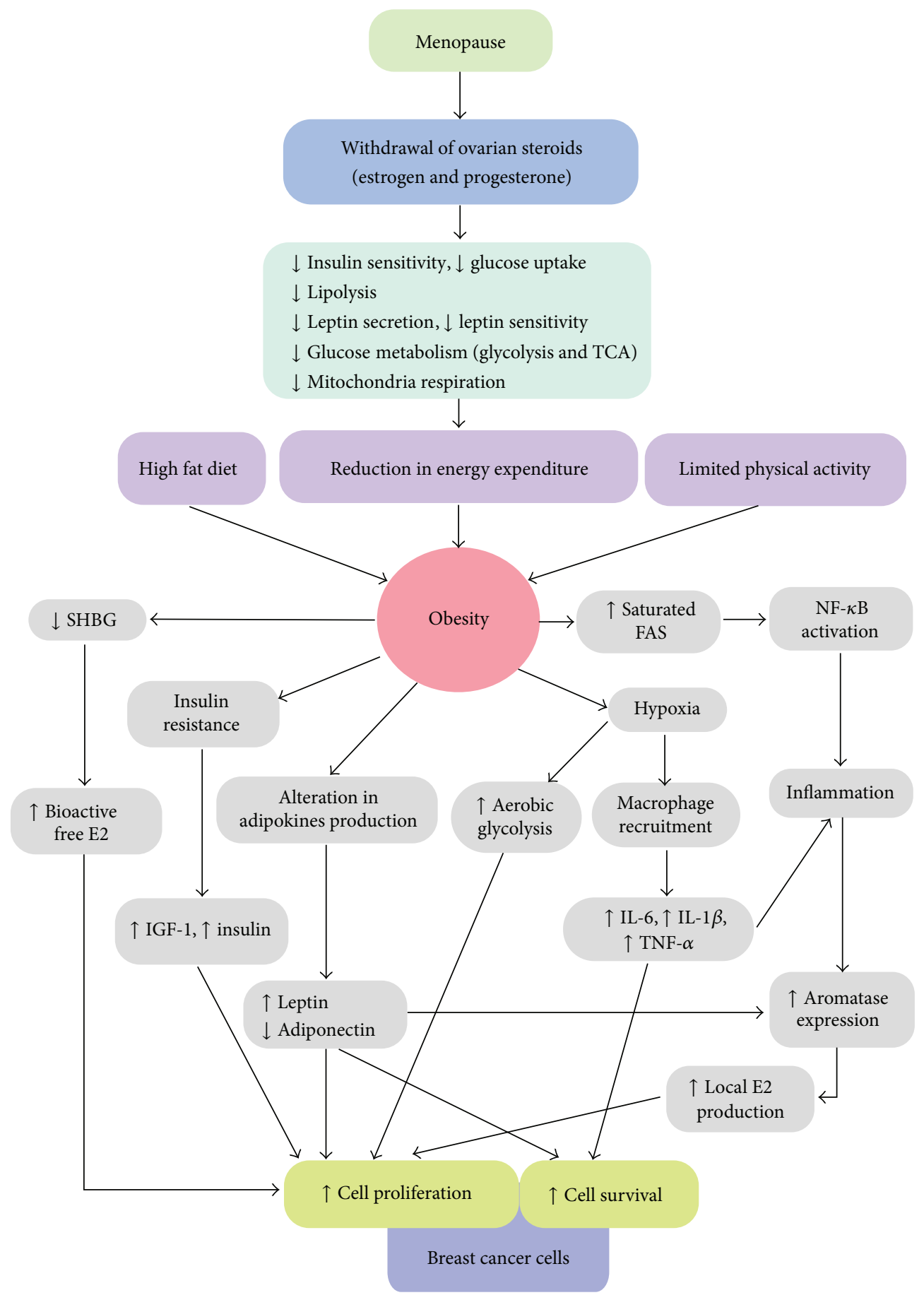

FIGURE 1: Diagram linking menopause and alterations in cellular metabolism with obesity and breast cancer. FAS: saturated fatty acid; TCA: tricarboxylic acid cycle; TNF $\alpha$ : tumor necrosis factor $\alpha$; IL-1: interleukin-1; IL-6, interleukin-6; SHBG: sex hormone binding globulin; E2: estradiol; IGF-1: insulin-like-growth-factor-1.

fully exploit their possible beneficial effects after menopause. Studies suggested that AF2 of $\mathrm{ER} \alpha$ is required to mediate E2 beneficial metabolic effects such as insulin sensitivity and energy expenditure, in an ERE-independent mechanism [68]. However, a detailed molecular mechanism of how $\mathrm{ER} \alpha-\mathrm{AF} 2$ is involved in these effects remains unclear. Better understanding of this molecular mechanism could help us develop a specific ligand that could specifically harness beneficial metabolic effects of ER without its harmful side effects.

Leptin plays a significant role in breast cancer development and progression [117]. Leptin stimulates production of proinflammatory cytokines and promotes cell proliferation and angiogenesis in breast cancer [117]. E2/ER stimulates 
leptin production both in human subjects and in in vivo animal models [118]. However, a detailed molecular mechanism of how E2 induces leptin expression and promotes leptin sensitivity is still to be explored. Better understanding of how E2/ER increases leptin levels could help devise new strategies for breast cancer prevention and reduce breast cancer incidence in obese postmenopausal patients.

How progesterone/PR affects cellular metabolism remains unclear. However, a recent study in an overfeeding OVX obese rat model for postmenopausal obesity showed that mammary tumors from obese rats with high energy excess overexpressed PR, mostly in form of the PR-A isoform [20]. The association between high PR expression and obesity or overfeeding is an interesting area of study. PR+ tumors showed an almost 50\% increase in glucose uptake and lower retention of dietary fat as compared to PR- tumors [20]. Whether PR directly or indirectly influences cellular metabolism or whether PR-B could exert similar metabolic effects in breast cancer is under investigation. Future studies will be required to unravel the association between high PR expression and glucose metabolism in breast cancer cells. In addition, it will be interesting to examine how expression of different PR isoforms affects breast cancer cell metabolism.

Progesterone/PR has an anti-inflammatory role in several animal models and in breast cancer cells [110, 111, 119]. Since obesity can induce a state of chronic inflammation [13], it would be interesting if we could take advantage of PR's antiinflammatory function to reduce inflammation caused by obesity. Additional studies will be necessary to determine detailed molecular mechanisms of how PR exerts its antiinflammatory function and to enable the design of specific PR ligands that specifically activate PR's anti-inflammatory activity. Metformin, the antidiabetic drug, has been shown to decrease PR expression and induce regression of mammary tumors and endometrial cancer $[20,120]$. While a recent study suggested that metformin promotes PR expression by increasing AMP-activated protein kinase (AMPK) phosphorylation and by inhibiting the MTOR pathway [120]. Future studies will be needed to determine the molecular mechanism of how metformin affects breast cancer growth and PR expression.

Depletion of ovarian sex steroids, E2 and progesterone, in combination with limited physical activity and high fat diet after menopause could cause several metabolic changes that facilitate weight gain and obesity. Obesity in E2 and progesterone deprived states in postmenopausal women may cause imbalance in homeostasis and changes in epithelial cells, stromal cells and adipocytes in the breasts that promote the growth and survival of receptor positive breast cancer cells (Figure 1). Better understanding of molecular mechanisms and signaling pathways that mediate these effects will help us to design better cancer prevention and treatment strategies for postmenopausal breast cancer.

\section{Conflict of Interests}

The authors declare that there is no conflict of interests regarding the publication of this paper.

\section{Acknowledgments}

The authors thank Dr. Gary C. Chamness for his comments and helpful editing of the paper. This work was supported by Ratchadaphisek Somphot Faculty Development Fund (GDNS 55-043-37-003) \& Ratchadaphisek Somphot Endowment Fund (R_007_2556) to Viroj Boonyaratanakornkit and Doctoral Degree Chulalongkorn University 100th Year Birthday Anniversary Scholarship (GCUGE1125561006D) to Prangwan Pateetin.

\section{References}

[1] T. Kelly, W. Yang, C.-S. Chen, K. Reynolds, and J. He, "Global burden of obesity in 2005 and projections to 2030," International Journal of Obesity, vol. 32, no. 9, pp. 1431-1437, 2008.

[2] Y. C. Wang, K. McPherson, T. Marsh, S. L. Gortmaker, and M. Brown, "Health and economic burden of the projected obesity trends in the USA and the UK," The Lancet, vol. 378, no. 9793, pp. 815-825, 2011.

[3] R. K. Masters, E. N. Reither, D. A. Powers, Y. C. Yang, A. E. Burger, and B. G. Link, "The impact of obesity on US mortality levels: the importance of age and cohort factors in population estimates," American Journal of Public Health, vol. 103, no. 10, pp. 1895-1901, 2013.

[4] E. E. Calle and R. Kaaks, "Overweight, obesity and cancer: epidemiological evidence and proposed mechanisms," Nature Reviews Cancer, vol. 4, no. 8, pp. 579-591, 2004.

[5] E. E. Calle, C. Rodriguez, K. Walker-Thurmond, and M. J. Thun, "Overweight, obesity, and mortality from cancer in a prospectively studied cohort of U.S. Adults," The New England Journal of Medicine, vol. 348, no. 17, pp. 1625-1638, 2003.

[6] A. G. Renehan, M. Tyson, M. Egger, R. F. Heller, and M. Zwahlen, "Body-mass index and incidence of cancer: a systematic review and meta-analysis of prospective observational studies," The Lancet, vol. 371, no. 9612, pp. 569-578, 2008.

[7] M. Protani, M. Coory, and J. H. Martin, "Effect of obesity on survival of women with breast cancer: systematic review and meta-analysis," Breast Cancer Research and Treatment, vol. 123, no. 3, pp. 627-635, 2010.

[8] A. Zeleniuch-Jacquotte, R. E. Shore, K. L. Koenig et al., "Postmenopausal levels of oestrogen, androgen, and SHBG and breast cancer: long-term results of a prospective study," British Journal of Cancer, vol. 90, no. 1, pp. 153-159, 2004.

[9] T. J. Key, P. N. Appleby, G. K. Reeves et al., "Body mass index, serum sex hormones, and breast cancer risk in postmenopausal women," Journal of the National Cancer Institute, vol. 95, no. 16, pp. 1218-1226, 2003.

[10] S. Tretli, T. Haldorsen, and L. Ottestad, "The effect of premorbid height and weight on the survival of breast cancer patients," British Journal of Cancer, vol. 62, no. 2, pp. 299-303, 1990.

[11] V. Rosato, C. Bosetti, R. Talamini et al., "Metabolic syndrome and the risk of breast cancer in postmenopausal women," Annals of Oncology, vol. 22, no. 12, pp. 2687-2692, 2011.

[12] C. K. Glass and J. M. Olefsky, "Inflammation and lipid signaling in the etiology of insulin resistance," Cell Metabolism, vol. 15, no. 5, pp. 635-645, 2012.

[13] E. R. Simpson and K. A. Brown, "Minireview: obesity and breast cancer: a tale of inflammation and dysregulated metabolism," Molecular Endocrinology, vol. 27, no. 5, pp. 715-725, 2013. 
[14] R. A. Cairns, I. S. Harris, and T. W. Mak, "Regulation of cancer cell metabolism," Nature Reviews Cancer, vol. 11, no. 2, pp. 8595, 2011.

[15] S. Basu, R. Nachat-Kappes, F. Caldefie-Chézet, and M.-P. Vasson, "Eicosanoids and adipokines in breast cancer: from molecular mechanisms to clinical considerations," Antioxidants \& Redox Signaling, vol. 18, no. 3, pp. 323-360, 2013.

[16] O. Warburg, "On the origin of cancer cells," Science, vol. 123, no. 3191, pp. 309-314, 1956.

[17] P. P. Hsu and D. M. Sabatini, "Cancer cell metabolism: warburg and beyond," Cell, vol. 134, no. 5, pp. 703-707, 2008.

[18] S. Mazurek, "Pyruvate kinase type M2: a key regulator of the metabolic budget system in tumor cells," The International Journal of Biochemistry \& Cell Biology, vol. 43, no. 7, pp. 969980, 2011.

[19] H. R. Christofk, M. G. Vander Heiden, M. H. Harris et al., "The M2 splice isoform of pyruvate kinase is important for cancer metabolism and tumour growth," Nature, vol. 452, no. 7184, pp. 230-233, 2008.

[20] E. D. Giles, E. A. Wellberg, D. P. Astling et al., "Obesity and overfeeding affecting both tumor and systemic metabolism activates the progesterone receptor to contribute to postmenopausal breast cancer," Cancer Research, vol. 72, no. 24, pp. 6490-6501, 2012.

[21] P. S. MacLean, E. D. Giles, G. C. Johnson et al., "A surprising link between the energetics of ovariectomy-induced weight gain and mammary tumor progression in obese rats," Obesity, vol. 18, no. 4, pp. 696-703, 2010.

[22] S. A. Salama, M. A. Mohammad, C. R. Diaz-Arrastia et al., "Estradiol-17 $\beta$ upregulates Pyruvate kinase M2 expression to co-activate estrogen receptor- $\alpha$ and to integrate metabolic reprogramming with the mitogenic response in endometrial cells," The Journal of Clinical Endocrinology Metabolism, vol. 99, no. 10, pp. 3790-3799, 2014.

[23] M. J. Khandekar, P. Cohen, and B. M. Spiegelman, "Molecular mechanisms of cancer development in obesity," Nature Reviews Cancer, vol. 11, no. 12, pp. 886-895, 2011.

[24] Y. Zhao, V. R. Agarwal, C. R. Mendelson, and E. R. Simpson, "Estrogen biosynthesis proximal to a breast tumor is stimulated by PGE2 via cyclic AMP, leading to activation of promoter II of the CYP19 (aromatase) gene," Endocrinology, vol. 137, no. 12, pp. 5739-5742, 1996.

[25] S. R. Salpeter, J. M. E. Walsh, T. M. Ormiston, E. Greyber, N. S. Buckley, and E. E. Salpeter, "Meta-analysis: effect of hormonereplacement therapy on components of the metabolic syndrome in postmenopausal women," Diabetes, Obesity and Metabolism, vol. 8, no. 5, pp. 538-554, 2006.

[26] A. B. Ropero, P. Alonso-Magdalena, I. Quesada, and A. Nadal, "The role of estrogen receptors in the control of energy and glucose homeostasis," Steroids, vol. 73, no. 9-10, pp. 874-879, 2008.

[27] C. Ohlsson, N. Hellberg, P. Parini et al., "Obesity and disturbed lipoprotein profile in estrogen receptor- $\alpha$-deficient male mice," Biochemical and Biophysical Research Communications, vol. 278, no. 3, pp. 640-645, 2000.

[28] P. A. Heine, J. A. Taylor, G. A. Iwamoto, D. B. Lubahn, and P. S. Cooke, "Increased adipose tissue in male and female estrogen receptor- $\alpha$ knockout mice," Proceedings of the National Academy of Sciences of the United States of America, vol. 97, no. 23, pp. 12729-12734, 2000.

[29] A. Morishima, M. M. Grumbach, E. R. Simpson, C. Fisher, and K. Qin, "Aromatase deficiency in male and female siblings caused by a novel mutation and the physiological role of estrogens," The Journal of Clinical Endocrinology \& Metabolism, vol. 80, no. 12, pp. 3689-3698, 1995.

[30] E. P. Smith, J. Boyd, G. R. Frank et al., "Estrogen resistance caused by a mutation in the estrogen-receptor gene in a man," The New England Journal of Medicine, vol. 331, no. 16, pp. 10561061, 1994.

[31] G. Bryzgalova, H. Gao, B. Ahren et al., "Evidence that oestrogen receptor- $\alpha$ plays an important role in the regulation of glucose homeostasis in mice: insulin sensitivity in the liver," Diabetologia, vol. 49, no. 3, pp. 588-597, 2006.

[32] V. Ribas, B. G. Drew, J. A. Le et al., "Myeloid-specific estrogen receptor $\alpha$ deficiency impairs metabolic homeostasis and accelerates atherosclerotic lesion development," Proceedings of the National Academy of Sciences of the United States of America, vol. 108, no. 39, pp. 16457-16462, 2011.

[33] L. Zhu, W. C. Brown, Q. Cai et al., "Estrogen treatment after ovariectomy protects against fatty liver and may improve pathway-selective insulin resistance," Diabetes, vol. 62, no. 2, pp. 424-434, 2013.

[34] Q. Gao, G. Mezei, Y. Nie et al., "Anorectic estrogen mimics leptin's effect on the rewiring of melanocortin cells and Stat3 signaling in obese animals," Nature Medicine, vol. 13, no. 1, pp. 89-94, 2007.

[35] R. Yonezawa, T. Wada, N. Matsumoto et al., "Central versus peripheral impact of estradiol on the impaired glucose metabolism in ovariectomized mice on a high-fat diet," American Journal of Physiology: Endocrinology and Metabolism, vol. 303, no. 4, pp. E445-E456, 2012.

[36] M. Moreno, P. Ordoñez, A. Alonso, F. Díaz, J. Tolivia, and C. González, "Chronic $17 \beta$-estradiol treatment improves skeletal muscle insulin signaling pathway components in insulin resistance associated with aging," Age, vol. 32, no. 1, pp. 1-13, 2010.

[37] R. P. A. Barros and J.-Å. Gustafsson, "Estrogen receptors and the metabolic network," Cell Metabolism, vol. 14, no. 3, pp. 289-299, 2011.

[38] T. M. D’Eon, S. C. Souza, M. Aronovitz, M. S. Obin, S. K. Fried, and A. S. Greenberg, "Estrogen regulation of adiposity and fuel partitioning: evidence of genomic and non-genomic regulation of lipogenic and oxidative pathways," Journal of Biological Chemistry, vol. 280, no. 43, pp. 35983-35991, 2005.

[39] J.-Q. Chen, T. R. Brown, and J. Russo, "Regulation of energy metabolism pathways by estrogens and estrogenic chemicals and potential implications in obesity associated with increased exposure to endocrine disruptors," Biochimica et Biophysica Acta-Molecular Cell Research, vol. 1793, no. 7, pp. 1128-1143, 2009.

[40] E. Furman, E. Rushkin, R. Margalit, P. Bendel, and H. Degani, "Tamoxifen induced changes in MCF7 human breast cancer: In vitro and in vivo studies using nuclear magnetic resonance spectroscopy and imaging," The Journal of Steroid Biochemistry and Molecular Biology, vol. 43, no. 1-3, pp. 189-195, 1992.

[41] A. Kostanyan and K. Nazaryan, "Rat brain glycolysis regulation by estradiol-17 $\beta$," Biochimica et Biophysica Acta (BBA)Molecular Cell Research, vol. 1133, no. 3, pp. 301-306, 1992.

[42] R. Pastorelli, D. Carpi, L. Airoldi et al., "Proteome analysis for the identification of in vivo estrogen-regulated proteins in bone," Proteomics, vol. 5, no. 18, pp. 4936-4945, 2005.

[43] T. Beckett, A. Tchernof, and M. J. Toth, "Effect of ovariectomy and estradiol replacement on skeletal muscle enzyme activity in female rats," Metabolism: Clinical and Experimental, vol. 51, no. 11, pp. 1397-1401, 2002. 
[44] C. Stirone, S. P. Duckles, D. N. Krause, and V. Procaccio, "Estrogen increases mitochondrial efficiency and reduces oxidative stress in cerebral blood vessels," Molecular Pharmacology, vol. 68, no. 4, pp. 959-965, 2005.

[45] J. Nilsen, R. W. Irwin, T. K. Gallaher, and R. D. Brinton, "Estradiol in vivo regulation of brain mitochondrial proteome," The Journal of Neuroscience, vol. 27, no. 51, pp. 14069-14077, 2007.

[46] S.-H. Yang, R. Liu, E. J. Perez et al., "Mitochondrial localization of estrogen receptor $\beta$," Proceedings of the National Academy of Sciences of the United States of America, vol. 101, no. 12, pp. 41304135, 2004.

[47] T. A. Milner, K. Ayoola, C. T. Drake et al., "Ultrastructural localization of estrogen receptor $\beta$ immunoreactivity in the rat hippocampal formation," Journal of Comparative Neurology, vol. 491, no. 2, pp. 81-95, 2005.

[48] J. Q. Chen, M. Eshete, W. L. Alworth, and J. D. Yager, “Binding of MCF-7 cell mitochondrial proteins and recombinant human estrogen receptors $\alpha$ and $\beta$ to human mitochondrial DNA estrogen response elements," Journal of Cellular Biochemistry, vol. 93, no. 2, pp. 358-373, 2004.

[49] A. Pedram, M. Razandi, D. C. Wallace, and E. R. Levin, "Functional estrogen receptors in the mitochondria of breast cancer cells," Molecular Biology of the Cell, vol. 17, no. 5, pp. 21252137, 2006.

[50] S. Solakidi, A.-M. G. Psarra, and C. E. Sekeris, "Differential subcellular distribution of estrogen receptor isoforms: localization of ER $\alpha$ in the nucleoli and ER $\beta$ in the mitochondria of human osteosarcoma SaOS-2 and hepatocarcinoma HepG2 cell lines," Biochimica et Biophysica Acta-Molecular Cell Research, vol. 1745, no. 3, pp. 382-392, 2005.

[51] C. M. van Itallie and P. S. Dannies, "Estrogen induces accumulation of the mitochondrial ribonucleic acid for subunit II of cytochrome oxidase in pituitary tumor cells," Molecular Endocrinology, vol. 2, no. 4, pp. 332-337, 1988.

[52] J.-Q. Chen, P. A. Russo, C. Cooke, I. H. Russo, and J. Russo, "ER $\beta$ shifts from mitochondria to nucleus during estrogen-induced neoplastic transformation of human breast epithelial cells and is involved in estrogen-induced synthesis of mitochondrial respiratory chain proteins," Biochimica et Biophysica ActaMolecular Cell Research, vol. 1773, no. 12, pp. 1732-1746, 2007.

[53] R. D. Brinton, "Estrogen regulation of glucose metabolism and mitochondrial function: therapeutic implications for prevention of Alzheimer's disease," Advanced Drug Delivery Reviews, vol. 60, no. 13-14, pp. 1504-1511, 2008.

[54] K. Toda, K. Takeda, S. Akira et al., "Alternations in hepatic expression of fatty-acid metabolizing enzymes in ArKO mice and their reversal by the treatment with $17 \beta$-estradiol or a peroxisome proliferator," The Journal of Steroid Biochemistry and Molecular Biology, vol. 79, no. 1-5, pp. 11-17, 2001.

[55] Y. Kamei, M. Suzuki, H. Miyazaki et al., "Ovariectomy in mice decreases lipid metabolism-related gene expression in adipose tissue and skeletal muscle with increased body fat," Journal of Nutritional Science and Vitaminology, vol. 51, no. 2, pp. 110-117, 2005.

[56] J. R. Rettberg, J. Yao, and R. D. Brinton, "Estrogen: a master regulator of bioenergetic systems in the brain and body," Frontiers in Neuroendocrinology, vol. 35, no. 1, pp. 8-30, 2014.

[57] Y. Zhou and L. Rui, "Leptin signaling and leptin resistance," Frontiers of Medicine, vol. 7, no. 2, pp. 207-222, 2013.
[58] L. M. Brown, L. Gent, K. Davis, and D. J. Clegg, "Metabolic impact of sex hormones on obesity," Brain Research, vol. 1350, pp. 77-85, 2010.

[59] S. C. Hong, S. W. Yoo, G. J. Cho et al., "Correlation between estrogens and serum adipocytokines in premenopausal and postmenopausal women," Menopause, vol. 14, no. 5, pp. 835840, 2007.

[60] A. J. G. Hanley, D. Bowden, L. E. Wagenknecht et al., "Associations of adiponectin with body fat distribution and insulin sensitivity in nondiabetic Hispanics and African-Americans," The Journal of Clinical Endocrinology and Metabolism, vol. 92, no. 7, pp. 2665-2671, 2007.

[61] N. J. Tomicek, T. S. Lancaster, and D. H. Korzick, "Increased estrogen receptor $\beta$ in adipose tissue is associated with increased intracellular and reduced circulating adiponectin protein levels in aged female rats," Gender Medicine, vol. 8, no. 5, pp. 325-333, 2011.

[62] A. Foryst-Ludwig, M. Clemenz, S. Hohmann et al., "Metabolic actions of estrogen receptor beta $(\mathrm{ER} \beta)$ are mediated by a negative cross-talk with PPAR $\gamma$," PLoS Genetics, vol. 4, no. 6, Article ID e1000108, 2008.

[63] V. Boonyaratanakornkit, "Mechanisms of estrogen receptor extranuclear signaling in human diseases," in Estrogen Receptors: Mechanisms, Structure and Role in Diseases, G. Chen, Ed., pp. 11-28, Nova Science Publishers, New York, NY, USA, 2012.

[64] M. Beato and J. Klug, "Steroid hormone receptors: an update," Human Reproduction Update, vol. 6, no. 3, pp. 225-236, 2000.

[65] L. Tora, J. White, C. Brou et al., "The human estrogen receptor has two independent nonacidic transcriptional activation functions," Cell, vol. 59, no. 3, pp. 477-487, 1989.

[66] V. Boonyaratanakornkit, "Scaffolding proteins mediating membrane-initiated extra-nuclear actions of estrogen receptor," Steroids, vol. 76, no. 9, pp. 877-884, 2011.

[67] V. Boonyaratanakornkit and D. P. Edwards, "Receptor mechanisms mediating non-genomic actions of sex steroids," Seminars in Reproductive Medicine, vol. 25, no. 3, pp. 139-153, 2007.

[68] S. Handgraaf, E. Riant, A. Fabre et al., "Prevention of obesity and insulin resistance by estrogens requires $\mathrm{ER} \alpha$ activation function-2 (ER $\alpha \mathrm{AF}-2)$, whereas ER $\alpha \mathrm{AF}-1$ is dispensable," Diabetes, vol. 62, no. 12, pp. 4098-4108, 2013.

[69] C. J. Park, Z. Zhao, C. Glidewell-Kenney et al., "Genetic rescue of nonclassical ER $\alpha$ signaling normalizes energy balance in obese Er $\alpha$-null mutant mice," The Journal of Clinical Investigation, vol. 121, no. 2, pp. 604-612, 2011.

[70] T. Fujita, Y. Kobayashi, O. Wada et al., "Full activation of estrogen receptor $\alpha$ activation function-1 induces proliferation of breast cancer cells," Journal of Biological Chemistry, vol. 278, no. 29, pp. 26704-26714, 2003.

[71] T. Wada, H. Tsuneki, and T. Sasaoka, "New insights into metabolic regulation via bifurcated function of estrogen receptor a," Diabetes, vol. 62, no. 12, pp. 3996-3998, 2013.

[72] P. Kastner, A. Krust, B. Turcotte et al., "Two distinct estrogenregulated promoters generate transcripts encoding the two functionally different human progesterone receptor forms A and B," EMBO Journal, vol. 9, no. 5, pp. 1603-1614, 1990.

[73] K. M. Scarpin, J. D. Graham, P. A. Mote, and C. L. Clarke, "Progesterone action in human tissues: regulation by progesterone receptor (PR) isoform expression, nuclear positioning and coregulator expression," Nuclear Receptor Signaling, vol. 7, article e009, 2009. 
[74] B. Mulac-Jericevic, R. A. Mullinax, F. J. DeMayo, J. P. Lydon, and O. M. Conneely, "Subgroup of reproductive functions of progesterone mediated by progesterone receptor-B isoform," Science, vol. 289, no. 5485, pp. 1751-1754, 2000.

[75] B. Mulac-Jericevic, J. P. Lydon, F. J. DeMayo, and O. M. Conneely, "Defective mammary gland morphogenesis in mice lacking the progesterone receptor B isoform," Proceedings of the National Academy of Sciences of the United States of America, vol. 100, no. 17, pp. 9744-9749, 2003.

[76] V. Boonyaratanakornkit, M. P. Scott, V. Ribon et al., "Progesterone receptor contains a proline-rich motif that directly interacts with $\mathrm{SH} 3$ domains and activates c-Src family tyrosine kinases," Molecular Cell, vol. 8, no. 2, pp. 269-280, 2001.

[77] R. P. Carnevale, C. J. Proietti, M. Salatino et al., "Progestin effects on breast cancer cell proliferation, proteases activation, and in vivo development of metastatic phenotype all depend on progesterone receptor capacity to activate cytoplasmic signaling pathways," Molecular Endocrinology, vol. 21, no. 6, pp. 13351358, 2007.

[78] V. Boonyaratanakornkit, E. McGowan, L. Sherman, M. A. Mancini, B. J. Cheskis, and D. P. Edwards, "The role of extranuclear signaling actions of progesterone receptor in mediating progesterone regulation of gene expression and the cell cycle," Molecular Endocrinology, vol. 21, no. 2, pp. 359-375, 2007.

[79] J. K. Richer, B. M. Jacobsen, N. G. Manning, M. G. Abel, D. M. Wolf, and K. B. Horwitz, "Differential gene regulation by the two progesterone receptor isoforms in human breast cancer cells," Journal of Biological Chemistry, vol. 277, no. 7, pp. 52095218, 2002.

[80] N. F. Butte, "Carbohydrate and lipid metabolism in pregnancy: normal compared with gestational diabetes mellitus," The American Journal of Clinical Nutrition, vol. 71, no. 5, pp. 1256s-1261s, 2000.

[81] American Diabetes Association, "Gestational diabetes mellitus," Diabetes Care, vol. 27, supplement 1, pp. S88-S90, 2004.

[82] C. Gonzalez, A. Alonso, N. Alvarez et al., "Role of $17 \beta$ estradiol and/or progesterone on insulin sensitivity in the rat: Implications during pregnancy," Journal of Endocrinology, vol. 166, no. 2, pp. 283-291, 2000.

[83] S. E. Campbell and M. A. Febbraio, "Effect of the ovarian hormones on GLUT4 expression and contraction-stimulated glucose uptake," The American Journal of PhysiologyEndocrinology and Metabolism, vol. 282, no. 5, pp. E1139-E1146, 2002.

[84] S. E. Campbell and M. A. Febbraio, "Effects of ovarian hormones on exercise metabolism," Current Opinion in Clinical Nutrition \& Metabolic Care, vol. 4, no. 6, pp. 515-520, 2001.

[85] I. R. Schlaepfer, C. A. Hitz, M. A. Gijón, B. C. Bergman, R. H. Eckel, and B. M. Jacobsen, "Progestin modulates the lipid profile and sensitivity of breast cancer cells to docetaxel," Molecular and Cellular Endocrinology, vol. 363, no. 1-2, pp. 111-121, 2012.

[86] F. Picard, M. Wanatabe, K. Schoonjans, J. Lydon, B. W. O’Malley, and J. Auwerx, "Progesterone receptor knockout mice have an improved glucose homeostasis secondary to $\beta$-cell proliferation," Proceedings of the National Academy of Sciences of the United States of America, vol. 99, no. 24, pp. 15644-15648, 2002.

[87] R. Zhou, X. Yao, X. Xu et al., "Blockage of progesterone receptor effectively protects pancreatic islet beta cell viability," Steroids, vol. 78, no. 10, pp. 987-995, 2013.

[88] J. Gao, J. Mazella, M. Tang, and L. Tseng, "Ligand-activated progesterone receptor isoform hPR-A is a stronger transactivator than hPR-B for the expression of IGFBP-1 (insulin-like growth factor binding protein-1) in human endometrial stromal cells," Molecular Endocrinology, vol. 14, no. 12, pp. 1954-1961, 2000.

[89] J. Gao and L. Tseng, "Progesterone receptor (PR) inhibits expression of insulin-like growth factor-binding protein-1 (IGFBP-1) in human endometrial cell line HEC-1B: characterization of the inhibitory effect of PR on the distal promoter region of the IGFP-1 gene," Molecular Endocrinology, vol. 11, no. 7, pp. 973-979, 1997.

[90] S. I. Grivennikov, F. R. Greten, and M. Karin, "Immunity, Inflammation, and Cancer," Cell, vol. 140, no. 6, pp. 883-899, 2010.

[91] J. Yin, Z. Gao, Q. He, D. Zhou, Z. Guo, and J. Ye, "Role of hypoxia in obesity-induced disorders of glucose and lipid metabolism in adipose tissue," American Journal of Physiology: Endocrinology and Metabolism, vol. 296, no. 2, pp. E333-E342, 2009.

[92] H. Wen, D. Gris, Y. Lei et al., "Fatty acid-induced NLRP3-ASC inflammasome activation interferes with insulin signaling," Nature Immunology, vol. 12, no. 5, pp. 408-415, 2011.

[93] K. Subbaramaiah, P. G. Morris, X. K. Zhou et al., "Increased levels of COX-2 and prostaglandin $\mathrm{E}_{2}$ contribute to elevated aromatase expression in inflamed breast tissue of obese women," Cancer Discovery, vol. 2, no. 4, pp. 356-365, 2012.

[94] K. A. Brown and E. R. Simpson, "Obesity and breast cancer: progress to understanding the relationship," Cancer Research, vol. 70, no. 1, pp. 4-7, 2010.

[95] S. E. Bulun, T. M. Price, J. Aitken, M. S. Mahendroo, and E. R. Simpson, "A link between breast cancer and local estrogen biosynthesis suggested by quantification of breast adipose tissue aromatase cytochrome $\mathrm{P} 450$ transcripts using competitive polymerase chain reaction after reverse transcription," The Journal of Clinical Endocrinology \& Metabolism, vol. 77, no. 6, pp. 16221628, 1993.

[96] J. S. O’Neill, R. A. Elton, and W. R. Miller, "Aromatase activity in adipose tissue from breast quadrants: a link with tumour site," British Medical Journal, vol. 296, no. 6624, pp. 741-743, 1988.

[97] P. G. Morris, C. A. Hudis, D. Giri et al., "Inflammation and increased aromatase expression occur in the breast tissue of obese women with breast cancer," Cancer Prevention Research, vol. 4, no. 7, pp. 1021-1029, 2011.

[98] S. C. Baumgarten and J. Frasor, "Minireview: inflammation: an instigator of more aggressive estrogen receptor (ER) positive breast cancers," Molecular Endocrinology, vol. 26, no. 3, pp. 360$371,2012$.

[99] H. Nakshatri, P. Bhat-Nakshatri, D. A. Martin, R. J. Goulet Jr., and G. W. Sledge Jr., "Constitutive activation of NF- $\kappa$ B during progression of breast cancer to hormone-independent growth," Molecular and Cellular Biology, vol. 17, no. 7, pp. 3629-3639, 1997.

[100] L. M. Morimoto, E. White, Z. Chen et al., "Obesity, body size, and risk of postmenopausal breast cancer: the women's health initiative (United States)," Cancer Causes and Control, vol. 13, no. 8, pp. 741-751, 2002.

[101] Y. Zhou, S. Eppenberger-Castori, C. Marx et al., "Activation of nuclear factor- $\kappa \mathrm{B}(\mathrm{NF} \kappa \mathrm{B})$ identifies a high-risk subset of hormone-dependent breast cancers," The International Journal of Biochemistry \& Cell Biology, vol. 37, no. 5, pp. 1130-1144, 2005.

[102] J. Frasor, A. E. Weaver, M. Pradhan, and K. Mehta, "Synergistic up-regulation of prostaglandin E synthase expression in breast cancer cells by $17 \beta$-estradiol and proinflammatory cytokines," Endocrinology, vol. 149, no. 12, pp. 6272-6279, 2008.

[103] S.-H. Chang, C. H. Liu, R. Conway et al., "Role of prostaglandin E2-dependent angiogenic switch in cyclooxygenase 2-induced 
breast cancer progression," Proceedings of the National Academy of Sciences of the United States of America, vol. 101, no. 2, pp. 591596, 2004.

[104] T. L. Larkins, M. Nowell, S. Singh, and G. L. Sanford, "Inhibition of cyclooxygenase-2 decreases breast cancer cell motility, invasion and matrix metalloproteinase expression," BMC Cancer, vol. 6, no. 1, article 181, 2006.

[105] K.-J. Park, V. Krishnan, B. W. O’Malley, Y. Yamamoto, and R. B. Gaynor, "Formation of an IKK $\alpha$-dependent transcription complex is required for estrogen receptor-mediated gene activation," Molecular Cell, vol. 18, no. 1, pp. 71-82, 2005.

[106] Z. Tu, S. Prajapati, K.-J. Park, N. J. Kelly, Y. Yamamoto, and R. B. Gaynor, "IKK $\alpha$ regulates estrogen-induced cell cycle progression by modulating E2F1 expression," The Journal of Biological Chemistry, vol. 281, no. 10, pp. 6699-6706, 2006.

[107] R. H. Straub, "The complex role of estrogens in inflammation," Endocrine Reviews, vol. 28, no. 5, pp. 521-574, 2007.

[108] D. Kalaitzidis and T. D. Gilmore, "Transcription factor crosstalk: The estrogen receptor and NF- $\kappa \mathrm{B}$," Trends in Endocrinology \& Metabolism, vol. 16, no. 2, pp. 46-52, 2005.

[109] K. W. Nettles, G. Gil, J. Nowak, R. Métivier, V. B. Sharma, and G. L. Greene, "CBP is a dosage-dependent regulator of nuclear factor- $\kappa \mathrm{B}$ suppression by the estrogen receptor," Molecular Endocrinology, vol. 22, no. 2, pp. 263-272, 2008.

[110] D. B. Hardy, B. A. Janowski, C.-C. Chen, and C. R. Mendelson, "Progesterone receptor inhibits aromatase and inflammatory response pathways in breast cancer cells via ligand-dependent and ligand-independent mechanisms," Molecular Endocrinology, vol. 22, no. 8, pp. 1812-1824, 2008.

[111] S. Kobayashi, J. P. Stice, D. Kazmin et al., "Mechanisms of progesterone receptor inhibition of inflammatory responses in cellular models of breast cancer," Molecular Endocrinology, vol. 24, no. 12, pp. 2292-2302, 2010.

[112] C. J. Creighton, C. Kent Osborne, M. J. van de Vijver et al., "Molecular profiles of progesterone receptor loss in human breast tumors," Breast Cancer Research and Treatment, vol. 114, no. 2, pp. 287-299, 2009.

[113] M. D. Althuis, J. H. Fergenbaum, M. Garcia-Closas, L. A. Brinton, M. P. Madigan, and M. E. Sherman, "Etiology of hormone receptor-defined breast cancer: a systematic review of the literature," Cancer Epidemiology, Biomarkers \& Prevention, vol. 13, no. 10, pp. 1558-1568, 2004.

[114] H. J. Thompson, J. N. McGinley, P. Wolfe, M. Singh, V. E. Steele, and G. J. Kelloff, "Temporal sequence of mammary intraductal proliferations, ductal carcinomas in situ and adenocarcinomas induced by 1-methyl-1-nitrosourea in rats," Carcinogenesis, vol. 19, no. 12, pp. 2181-2185, 1998.

[115] S. J. Santos, M. D. Aupperlee, J. Xie et al., "Progesterone receptor A-regulated gene expression in mammary organoid cultures," Journal of Steroid Biochemistry and Molecular Biology, vol. 115, no. 3, pp. 161-172, 2009.

[116] A. McTiernan, C. Kooperberg, E. White et al., "Recreational Physical Activity and the Risk of Breast Cancer in Postmenopausal Women: The Women's Health Initiative Cohort Study," Journal of the American Medical Association, vol. 290, no. 10, pp. 1331-1336, 2003.

[117] G. Newman and R. R. Gonzalez-Perez, "Leptin-cytokine crosstalk in breast cancer," Molecular and Cellular Endocrinology, vol. 382, no. 1, pp. 570-582, 2014.

[118] H. Shimizu, Y. Shimomura, Y. Nakanishi et al., "Estrogen increases in vivo leptin production in rats and human subjects," Journal of Endocrinology, vol. 154, no. 2, pp. 285-292, 1997.
[119] H. Tan, L. Yi, N. S. Rote, W. W. Hurd, and S. Mesiano, "Progesterone receptor-A and -B have opposite effects on proinflammatory gene expression in human myometrial cells: implications for progesterone actions in human pregnancy and parturition," The Journal of Clinical Endocrinology and Metabolism, vol. 97, no. 5, pp. E719-E730, 2012.

[120] Y. Xie, Y.-L. Wang, L. Yu et al., "Metformin promotes progesterone receptor expression via inhibition of mammalian target of rapamycin (mTOR) in endometrial cancer cells," Journal of Steroid Biochemistry and Molecular Biology, vol. 126, no. 3, pp. 113-120, 2011. 


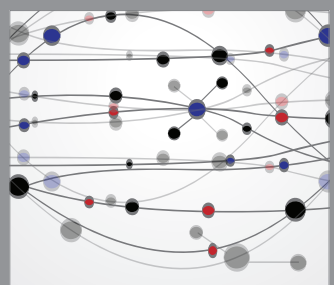

The Scientific World Journal
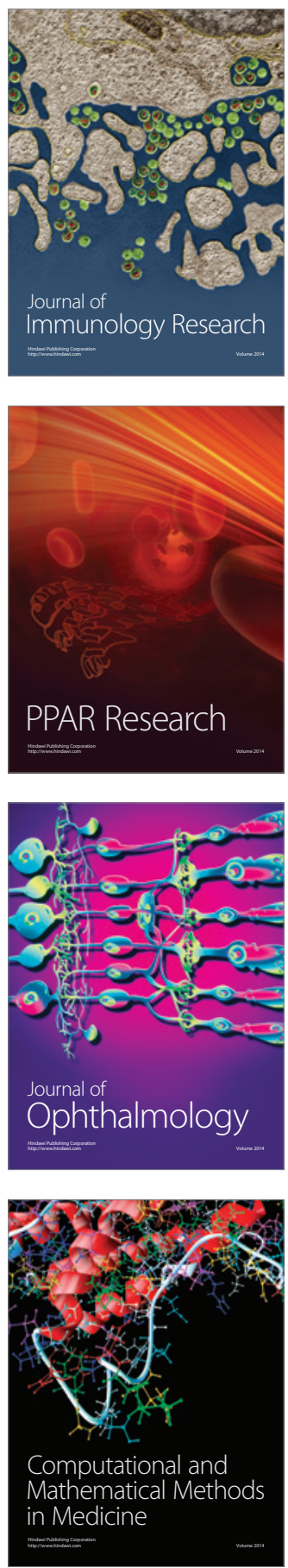

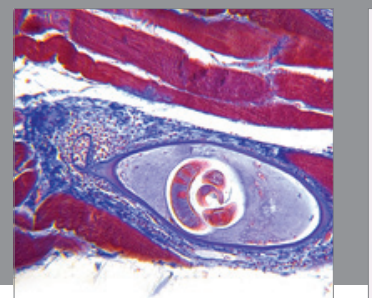

Gastroenterology

Research and Practice
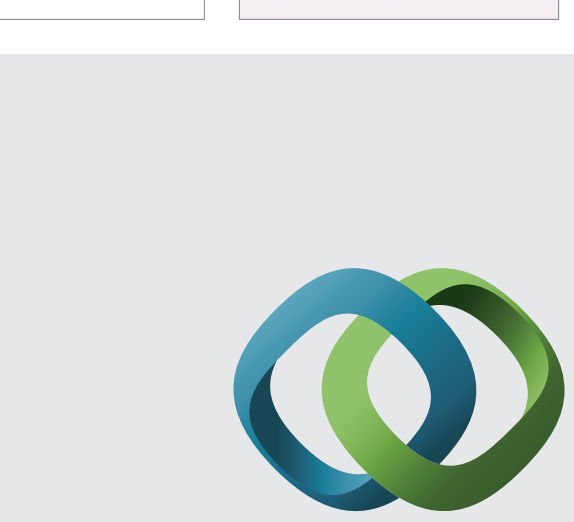

\section{Hindawi}

Submit your manuscripts at

http://www.hindawi.com
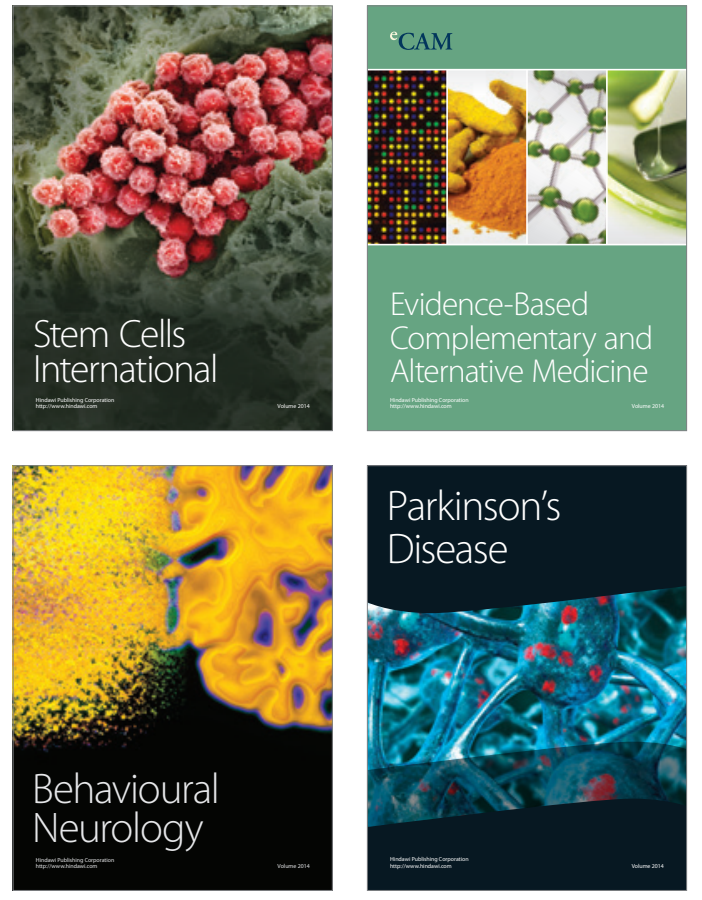
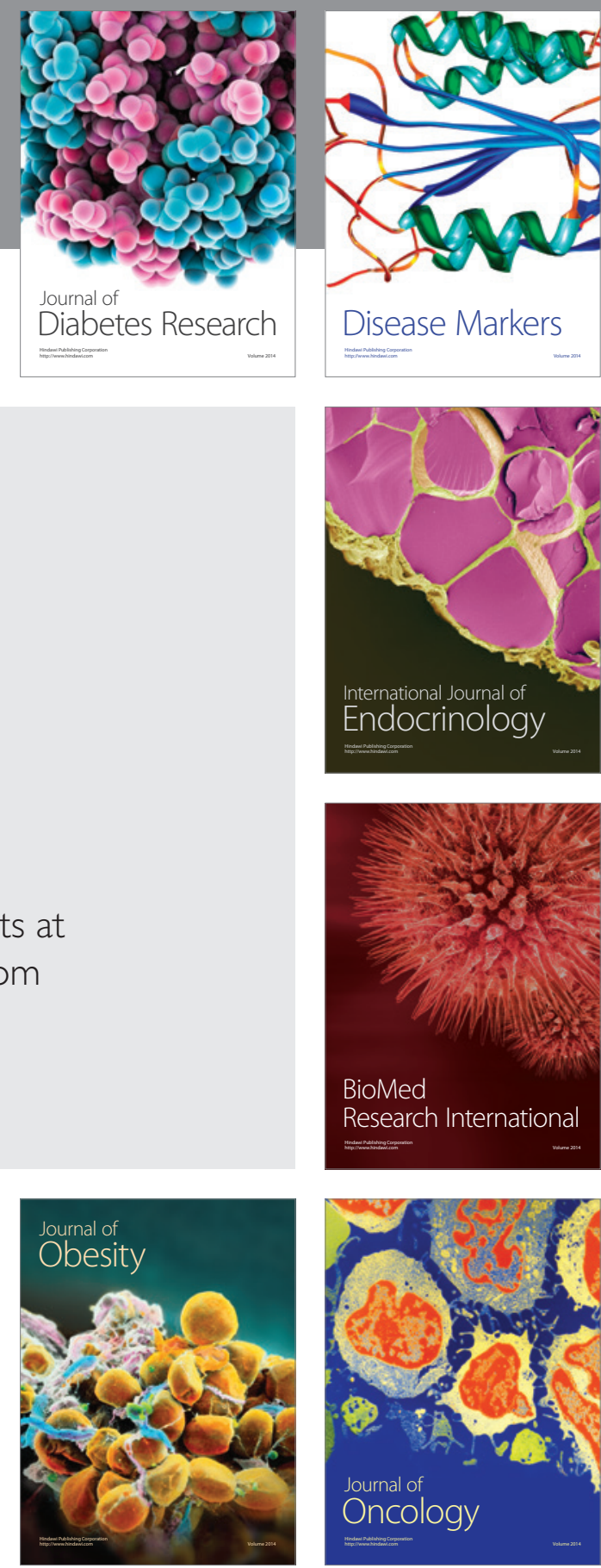

Disease Markers
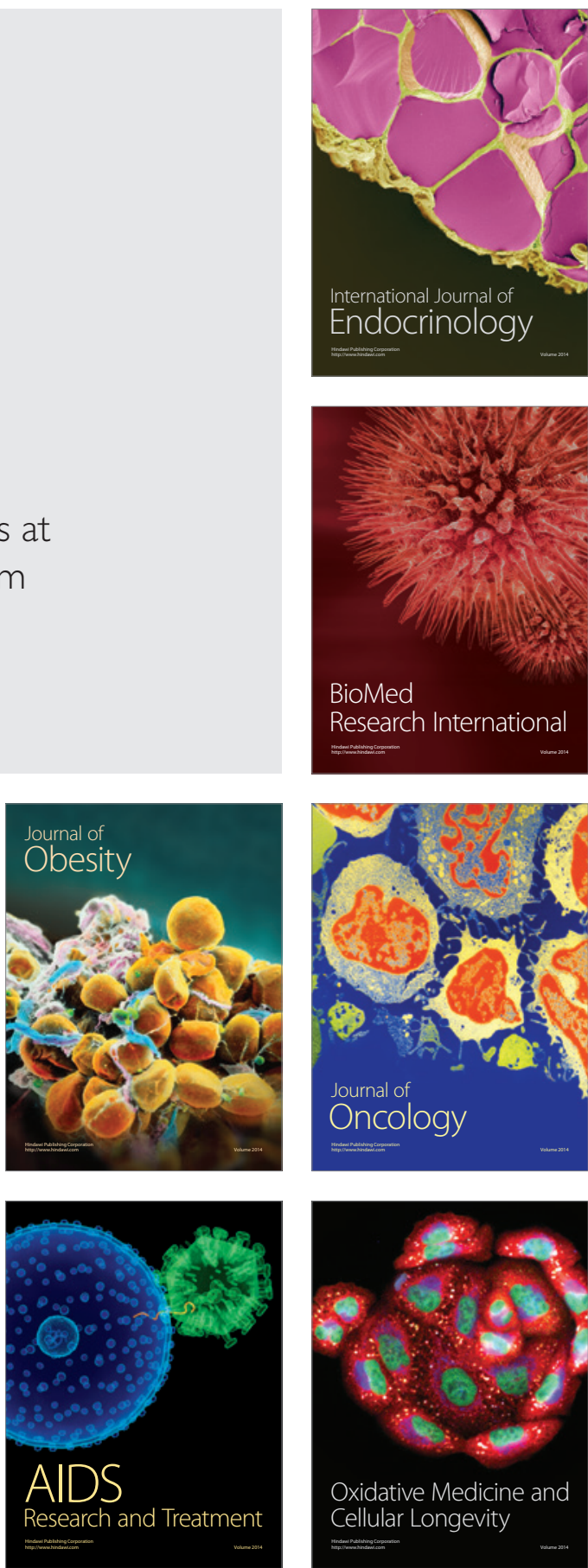